\title{
Estructura y sentido de la noticia televisiva: parámetros para la construcción y el análisis del mensaje en el entorno audiovisual
}

\author{
Luís Fernando Morales Morante \\ Universidad Autónoma de Barcelona \\ fernando.morales@uab.es
}

Recibido: 12 de diciembre de 2011

Aceptado: 24 de septiembre de 2012

\begin{abstract}
Resumen
La claridad y eficacia de la noticia audiovisual tiene su base en la noción estructuralista de organización de la información y se sirve de los recursos tecnológicos y de la técnica productiva para mejorar su acabado final. En el presente artículo se efectúa el análisis comparado de una noticia emitida en dos canales de cobertura nacional aplicando el Modelo de Construcción Informativa eficiente (MOCIAE). Los resultados indican el empleo de esquemas diferenciales en ambos medios: para la cobertura, la redacción de los textos, el ordenamiento de los datos y el empleo de recursos sintácticos y expresivos para dirigir la atención en ciertos aspectos preferenciales del acontecimiento representado, empleados en las diferentes etapas del proceso de producción de la noticia.
\end{abstract}

Palabras clave: noticia, información, mensaje audiovisual, eficacia, estructura

\section{Structure and meaning of television news: parameters for the construction and analysis of the message in the audiovisual environment}

\begin{abstract}
The clarity and effectiveness of audiovisual news is based on the structuralist notion of the organization and uses information technology resources and technology to improve their productive finish. In this paper the comparative analysis is made of a news broadcast on two channels with national coverage using the Building Information Model efficiency (MOCIAE). The results indicate the use of differential schemes in both ways: to cover the drafting of the order of the data and the use of syntactic and expressive resources to focus attention on certain aspects of the event preferential represented employees in the different stages of production of the news.
\end{abstract}

Keywords: news, information, audiovisual message, efficiency, structure

Referencia normalizada: MORALES MORANTE, Luis Fernando (2012): "Estructura y sentido de la noticia televisiva: parámetros para la construcción y el análisis del mensaje en el entorno audiovisual". Estudios sobre el mensaje periodístico, vol. 18, núm. 2 (julio-diciembre), págs.: 805-821. Madrid, Servicio de Publicaciones de la Universidad Complutense.

Sumario: 1. Introducción. 2. Objetivos. 3. Marco Teórico; 3.1. El mensaje-noticia como proceso y estructura; 3.2. Base estructuralista de los géneros; 3.3. El Montaje como herramienta generadora de estructuras; 3.4. El Modelo de Construcción Informativa Audiovisual (MOCIAE). 4. Análisis comparativo. 5. Conclusiones. 6. Referencias bibliográficas.

\section{Introducción}

En las últimas dos décadas los cambios tecnológicos producidos por el traspaso de la sistema analógico hacia la norma digital han modificado profundamente las dinámicas de producción de mensajes audiovisuales en sus distintas fases. En el ámbito específico de la televisión y el vídeo informativos, la digitalización ha traído consigo nuevas herramientas para agilizar y mejorar la construcción y emisión de noticias, entrevistas 
y reportajes audiovisuales. Todos estos recursos además de optimizar los procesos productivos en términos de ahorro de tiempo y economía del equipo humano, son a su vez oportunidades para manejar mejor los contenidos de los mensajes, potenciar su eficacia e incrementar así la capacidad de competitividad entre las cadenas de televisión. La implantación de sistemas también resulta ideal para ejercer un control estricto e inmediato de lo que cada profesional realiza y del material que finalmente va a recibir el público, independientemente de la plataforma elegida para su emisión. Bajo estos condicionantes, la implantación tecnológica ha terminado redefiniendo las rutinas productivas y las funciones específicas que desempeñan los periodistas. La demanda de profesionales ha se decanta ahora por perfiles polivalentes, capacitados para resolver de forma inmediata cualquier inconveniente presentado en las distintas áreas y momentos del proceso de elaboración de piezas informativas. La jerarquización, el tratamiento y el estilo que finalmente adquiere la noticia, son definidos anticipadamente por los periodistas siguiendo rigurosos criterios editoriales predeterminados, de acuerdo con su línea y la intencionalidad comunicativa definida por los anunciantes y la segmentación de audiencias a la que se dirigen. Definir la organización funcional de todos estos elementos a lo largo del proceso productivo y comparar su aplicación en dos piezas informativas para la televisión es el objetivo central de la presente investigación. Esta comparación puede ser útil para mejorar los procesos productivos, la calidad del contenido, los tratamientos y la toma de decisiones en la elaboración de noticias para la televisión y de difusión por otros medios audiovisuales.

\section{Objetivos}

El presente artículo se plantea los siguientes tres objetivos de investigación:

1. Definir los rasgos formales y estructurales que definen la expresión informativa y estética de la noticia audiovisual, en sus diferentes fases de elaboración.

2. Efectuar un análisis comparativo del tratamiento periodístico de una noticia para la televisión -Huelga de Maestros en la ciudad de Madrid 2011- difundida por dos cadenas de televisión generalistas de España: Televisión Española y Antena 3, a partir de la aplicación del Modelo de Construcción Informativa Audiovisual Eficaz (MOCIAE) (MORALES, 2011).

3. Establecer a partir del resultado del análisis, los elementos característicos que tipifican el tratamiento del contenido, la forma externa y la manera particular como dichos rasgos son tratados y presentados al televidente por ambas cadenas.

\section{Marco Teórico}

\subsection{El mensaje-noticia como proceso y estructura}

Según las rutinas prácticas de redacción periodística (HuERTAS y Perona, 1999; MarTíNEZ, 1998; CEBRIÁN, 1992; VAN DIJK, 1990), la elaboración de noticias para la televisión se efectúa controlando principalmente dos niveles de estructuración de la información, la Macro estructura o Coherencia semántica global y la Micro estructura o Coherencia sintáctica. La primera hace referencia a cómo los elementos que componen un texto permiten deducir al lector o escucha que las diferentes partes forman un todo (Huertas y Perona, 1999). Según Van DijK, la macroestructura define no 
sólo lo que denominamos la organización temática del texto, sino también su coherencia global. Si el texto incluye proposiciones que no pueden subsumirse bajo un tema determinado o nuevo en una conversación, podemos decir que el hablante es incoherente o que no se atiene al tema del cual está hablando. (VAN DiJK, 1990: 47). Supone ordenar la información en bloques, apartados y conclusiones elegidos según su nivel de relevancia (CASSANY, 1987). Por su parte, la Micro estructura o coherencia sintáctica consiste en la concordancia existente entre las palabras y la relación entre las frases que componen cada una de las unidades subordinadas del mensaje sea este escrito o audiovisual (Huertas y Perona, 1999: 51; CeBrián, 1998: 77). Según WeSTLEY y MCLEAN (1957) el periodista desarrolla tres fases diferentes para articular el discurso: la Primera Fase se denomina Gatekeeper: selección de la información o Discurso Informacional, la Segunda es la Redacción del texto o Discurso Textual y la Tercera, la Locución de la noticia o Discurso Oral. Nosotros añadiríamos una cuarta fase: Discurso audiovisual, en la cual los elementos de la coherencia textual, se registran y exhiben a través de dos corrientes: imagen y sonido (MAY y BARNARD, 2003; SADOSKI y PAIVIO, 2001), añadiendo así una corriente significativa dual. Mas configura un modelo de noticia para la televisión articulando tres niveles: Informativo, Estructural y Superestructural (MAS, 2010), desarrollando una propuesta mejorada de la teoría estructural compleja (TABOADA y MANN, 2005) que sugiere también diferentes tipos de discurso en función del tipo de asociación de la información: «núcleo» o «satélite» a partir del grado de novedad que representa la información para el receptor.

Consecuentemente, el control de ambos niveles de estructuración del mensaje, Coherencia Semántica y Coherencia Sintáctica regula la construcción de un orden temático y jerárquico de los datos, fundamental para que el receptor ejecute una lectura e interpretación certera de los hechos representados en la pantalla. Si el texto, las imágenes y sonidos poseen un ordenamiento adecuado y cada una de sus partes mantiene una sucesión interna lógicamente organizada, será claro, preciso y coherente para el receptor.

\subsection{Base estructuralista de los géneros}

La matriz estructuralista de los mensajes informativos tiene su raigambre en los géneros narrativos y dramáticos más antiguos. El paradigma ternario clásico: Presentación - Nudo - Desenlace, propio de las historias argumentales (CHION, 2001, 143; QUINQUER, 2001, 133; FIELD; 2001, 117; VALE, 1996, 154), se modela para establecer una organización dosificada de la información en bloques, escenas y secuencias, tal como se organizan las películas y los programas de televisión. Este esquema es igualmente aplicable a la estructuración de las noticias. Mariano CEBRIÁN (1988: 201) articula la noticia en cuatro partes: Cabecera, Desarrollo, Transiciones internas y Cierre. PRADO (1981: 49) la condensa en tres: Entrada, Cuerpo y Cierra. La forma estructural y su extensión refleja la manera cómo se profundiza y desmenuzan los hechos en bloques de información adaptados a formatos comunicativos específicos.

\subsection{El Montaje como herramienta generadora de estructuras}

Otro punto de vista que valida esta noción estructural de los discursos se ha centrado también fuertemente en torno a las funciones discursivas del montaje audiovisual. Las teorías del montaje cinematográfico definen dos modalidades de construcción de sentido 
en los discursos, relacionadas con efectos concretos de comunicación. Una es el Montaje Narrativo. Hace referencia a la lógica, sucesión ordenada y coherente de las imágenes y sonidos, respetando el raccord o la continuidad que las interconecta (AMIEL, 2005: 27; MitRY, 2002: 426; MARTín, 1999: 144; BALÀzs, 1978: 91) La otra es el Montaje Expresivo e interviene en un segundo nivel de significación. Mientras el montaje narrativo ayudar a facilitar las operaciones cognitivas dirigidas a descifrar la información y facilitar su procesamiento eficaz, el montaje expresivo se orienta a producir significados más complejos, destacar valores estéticos relacionados con las operaciones de yuxtaposición y a la activación de estados emocionales en el espectador (MARTín, 1999: 145; BALÀZs, 1978: 91). En el caso del discurso noticioso, las variaciones en los parámetros semánticos, visuales y sonoros, así como las pausas y transiciones se definen e interpretan por los espectadores por ejemplo como: un cambio de locación, variación de tiempo, de tema, ingreso de una declaración o del periodista que cubre la información. La manera específica de diseñar la representación por la cámara se asienta en el seguimiento escrupuloso de las normas de la continuidad o raccord entre los planos y entre las distintas partes que conforman el mensaje. Múltiples autores insisten recurrentemente en el respeto «obligatorio» al eje de acción, la regla de los tercios, la regla de los $30^{\circ}$ (Reisz y Millar, 2003; SÁnchez, 2003; Rey, 2002; Millerson, 2001; MASCELli, 1988; WURTZEL, 1983), para exponer de forma fluida las acciones, porque estos esquemas son concordantes con nuestra forma natural de ver y procesar la realidad circundante. En los últimos años, diferentes estudios psicológicos (D‘YDEWALLE \& GERMEY, 2005; Sмітн, 2005) se han centrado en comprobar la eficacia de estas técnicas para determinar cómo percibimos los modelos construcción del espacio y tiempo o la concordancia entre las diversas partes del contenido interno en mensajes informativos.

\subsection{El Modelo de Construcción Informativa Audiovisual (MOCIAE)}

El Modelo de Construcción Informativa Audiovisual Eficaz (MOCIAE) (MoRALES, 2010a), es un esquema de articulación de noticias para la televisión diseñado para efectuar un seguimiento de las acciones realizadas en cada una de las fases del proceso de producción periodística. El modelo define las decisiones y procedimientos empleados para el control de la cobertura, estructuración, edición y emisión de las piezas informativas. Con esta herramienta es posible controlar en su totalidad y de manera eficiente la elaboración, el tratamiento y la puesta en pantalla del material audiovisual noticioso, permitiendo así calcular la carga del contenido, precisar los rasgos que definen la estructura y forma externa de la noticia. Este sistema facilita la tarea comparaciones entre productos, etc. Veamos separadamente los tres niveles y fases de aplicación que lo forman:

\section{- PRIMER NIVEL: PROCESO DE PRODUCCION INFORMATIVA}

El primer nivel está formado por cada una de las etapas convencionales de la producción informativa audiovisual. Comprende desde la cobertura o registro de la información hasta la etapa de la emisión o propagación de la noticia o producto terminado. Este proceso se divide en cuatro fases:

- FASE N ${ }^{\circ}$ 1: COBERTURA 
Consiste en el registro de imágenes y sonidos por el periodista/camarógrafo en el lugar de ocurrencia del hecho noticioso. En primer lugar se elije el Punto de vista o colocación de la cámara respecto de la acción, para efectuar un registro audiovisual acorde con lo que acontece en la realidad. En segundo lugar se genera el Registro del material: planos, tomas, audio, material de apoyo, etc. Luego se lleva a cabo el Registro de testimonios de los actores del acontecimiento, para ampliar, contrastar y profundizar los datos audiovisuales recogidos por el periodista. Eventualmente puede incluirse un Stand up del reportero frente a cámara, a manera de entrada o cierre de la noticia como evidencia directa de su presencia en escena.

- FASE N ${ }^{\circ}$ 2: ESTRUCTURACIÓN

En una segunda fase la labor del periodista se traslada al canal de televisión y se concentra en valorar íntegramente el material registrado para adecuarlo a las normas y convenciones del formato de emisión. Se pondera el grado de novedad, amplitud, interés noticiable y magnitud. Igualmente se define indiciariamente su Tratamiento y Sentido noticioso. Luego se visiona nuevamente el material, estableciendo una jerarquización de las diferentes partes o secciones del material producido, adecuándolo a los lineamientos estipulados. Se define la estructura global y el predominio de unos elementos sobre otros (locuciones, testimonios Stand up, sonidos de ambiente, efectos de librería, etc.), según su tiempo y momento de aparición. Estos criterios siguen habitualmente los modelos de análisis del texto de acuerdo con las teorías del montaje y de la teoría de la retórica (MANN Y THOMPSON, 1988; AMIEL, 2005: 27; MitRY, 2002: 426; MARTín, 1999: 144; BALÀZs, 1978: 91). En esta fase se elaboran los textos para ser locutados por el periodista. El tratamiento de la construcción textual ha de ser claro, conciso y directo (MARTíNEZ ALBERTOS: 1989), para garantizar la comprensión del sentido de la información.

- FASE No 3: EDICION

La tercera fase implica el modelado audiovisual de la noticia según las decisiones y criterios estructurales definidos en las dos etapas preliminares. Aquí el periodista, habitualmente acompañado del editor periodístico y el montador organiza el material disponible y construye la noticia siguiendo secuencialmente tres subetapas operacionales precisas (MORALES, 2000: 18; MILLERSON, 2001: 141). La Selección consiste en la elección de imágenes y sonidos atendiendo a su contenido periodístico y de combinación con el resto de sustancias icónico-auditivas. Luego se realiza el Ordenamiento u organización secuencial de la información. Se realiza de dos modalidades principales: la primera, siguiendo la misma cronología del registro; es decir, de la ocurrencia de los acontecimientos o bien apelando a recreaciones espacio-temporales que faciliten mejor su explicación. Finalmente, la tercera etapa consiste en la elección de la Duración de los fragmentos. El ajuste técnico para interconectar cada uno de los planos y sonido aprovechables, dándoles un tiempo exacto de exposición para formar una estructura rítmica y periodística ágil y dinámica para el espectador.

- FASE No 4: EMISION

En esta última etapa, se redefinen los tiempos y los criterios de ajuste sobre la base de los imprevistos y cambios producidos en la estructura del informativo, atendiendo a la llegada de otras noticias más importantes. Durante la Emisión, también se insertan los títulos y créditos a la noticia, para definir los datos de lugar, hora, nombre de 
las personas figurantes, entre otros; y situar más claramente los referentes de la cobertura y la presentación en el plató. Finalmente la tercera fase de la emisión consiste en la sonorización en directo de la noticia. Aunque esta etapa se realiza de habitualmente de manera previa y externa durante la postproducción, puede hacerse también durante la emisión en directo del informativo. Cumple la función de fortalecer el sentido y la carga expresiva del discurso así como para la construcción de atmósferas a través de las cuales el mensaje puede hacerse más explicito en su sentido y carácter con el uso de otros recursos: sonido ambiente, música y efectos, etc.

Como podemos constatar, este primer nivel de construcción de la noticia se limita prácticamente a ejecutar las diferentes etapas de su realización como pieza audiovisual, siguiendo el mismo proceso de otros discursos no informativos como programas de ficción, spots publicitarios, entre otros. Sin embargo, como es bien sabido, las funciones del periodista tienen incidencia directa en decisiones más complejas respecto del tratamiento de los contenidos y su forma de presentarlos. La ejecución de estas acciones se produce en un segundo nivel de articulación de la información.

\section{- SEGUNDO NIVEL: INTENCION INFORMATIVA}

En el segundo nivel la actividad se concentra en la producción de efectos de sentido más elevados a la simple estructura formal. Se trata de crear relaciones significativas entre las partes y los fragmentos. Para ello nos preguntamos: ¿Qué objetivo buscamos crear o producir en la audiencia? ¿Únicamente pretendemos relatar correctamente la noticia? ¿Intentamos trasmitir además relaciones de significado? Para conseguirlos adecuamos la estrategia según dos intenciones: Narrar y Emocionar.

La primera: Narrar, se restringe únicamente al rol estrictamente informativo del mensaje, persigue transmitir los hechos de forma lineal, concatenada y producir un significado claro del suceso.

La segunda Emocionar, pretende producir una connotación más expresiva del mensaje mediante la explotación de los mecanismos retóricos empleados previamente durante el rodaje o a posteriori, durante el montaje.

Una vez definido el objetivo de comunicación, definimos los procedimientos idóneos para organizar las sustancias informativas (ver Tabla 1). Para ello, se realiza un nuevo análisis de los materiales registrados, evaluando esta vez su grado específico de afinidad con la intención seleccionada. Este nuevo estudio, más profundo, sirve para verificar el carácter y la función semántica de cada fragmento para provocar un significado concreto al unirse con otros o bien dentro del conjunto de la secuencia.

Tabla $N^{\circ}$ 1: Cuadro resumen: Métodos asociativos y relacionales

\begin{tabular}{|l|l|l|}
\hline PROCEDIMIENTO & \multicolumn{1}{c|}{ MODALIDADES } & \multicolumn{1}{c|}{\begin{tabular}{c}
\multicolumn{1}{c|}{ FUNCION } \\
COMUNICATIVA
\end{tabular}} \\
\hline \multirow{2}{*}{ Narrar } & $\begin{array}{l}\text { 1. Lineal: Sucesión de imágenes o escenas } \\
\text { en orden cronológico. } \\
\text { 2. Invertido: Altera el orden natural, } \\
\text { comenzando por el final y finalizando con } \\
\text { la principio. }\end{array}$ & $\begin{array}{l}\text { Narrar una acción de } \\
\text { manera secuencial o } \\
\text { variando su orden lógico. }\end{array}$ \\
\hline
\end{tabular}




\begin{tabular}{|l|l|}
\hline & $\begin{array}{l}\text { 1. Paralelo: Dos o más acciones } \\
\text { independientes se desarrollan de modo } \\
\text { simultáneo. } \\
\text { 2. Semejanza } \\
\text { 3. Contraste }\end{array}$ \\
\hline
\end{tabular}

- TERCER NIVEL: SUJECION DE LA PERCEPCION ESPACIO-TEMPORAL

Ahora bien, una vez ejecutada la estrategia narrativa o emocional del mensaje, se despliega un tercer y último nivel de interacción, cuyo objetivo es reconstruir la impresión de realidad del conjunto, de toda la representación. Se contemplan aquí tres procedimientos específicos: Relaciones Espaciales, Temporales y de Apariencia Visual. Las Relaciones espaciales configuran nuestra impresión de la representación mediante la composición visual: ubicación de la cámara, distancia, cambios de perspectiva y relación de los personajes con el fondo escenográfico. Las Relaciones temporales dependen del planeamiento de rodaje y su devenir temporal que puede fortalecerse por el montaje y planeamiento estructural. Finalmente, las Relaciones de apariencia visual son recursos para crear nexos u oposiciones entre unidades para dinamizar el ritmo del mensaje. Este nivel verifica el cumplimiento de los parámetros de coherencia de las reglas de rodaje desarrolladas en el apartado 3.4.

En el siguiente gráfico (Gráfico $\mathrm{n}^{\mathrm{o}} 1$ ), puede apreciarse un esquema integral del modelo en el cual se explican los procedimientos y fases que se llevan a cabo en cada uno de los tres niveles de articulación.

Gráfico No 1: Modelo de Construcción Informativa Audiovisual Eficaz (MOCIAE) (MoRALES, 2010)

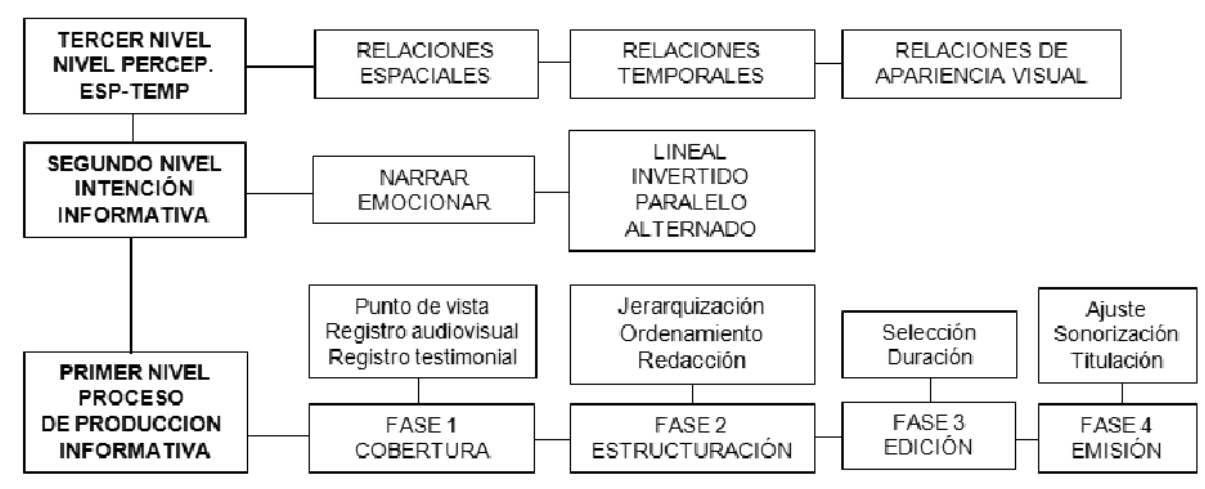

\section{Análisis comparativo}

Una vez definidos los ámbitos y procedimientos aplicativos del (MOCIAE), veamos su funcionamiento aplicándolo al análisis del tratamiento de una noticia emitida en dos medios de cobertura nacional: Televisión Española y Antena 3 (Tabla 2). La noticia seleccionada es la Huelga de profesores realizada en los colegios de la ciudad de Madrid el día 20 de setiembre de 2011, como protesta a los recortes presupuestales efectuados por la Comunidad de Madrid. 


\section{Primer Nivel: Proceso de Producción informativa}

Tabla 2: Análisis comparativo de la noticia TVE/A3

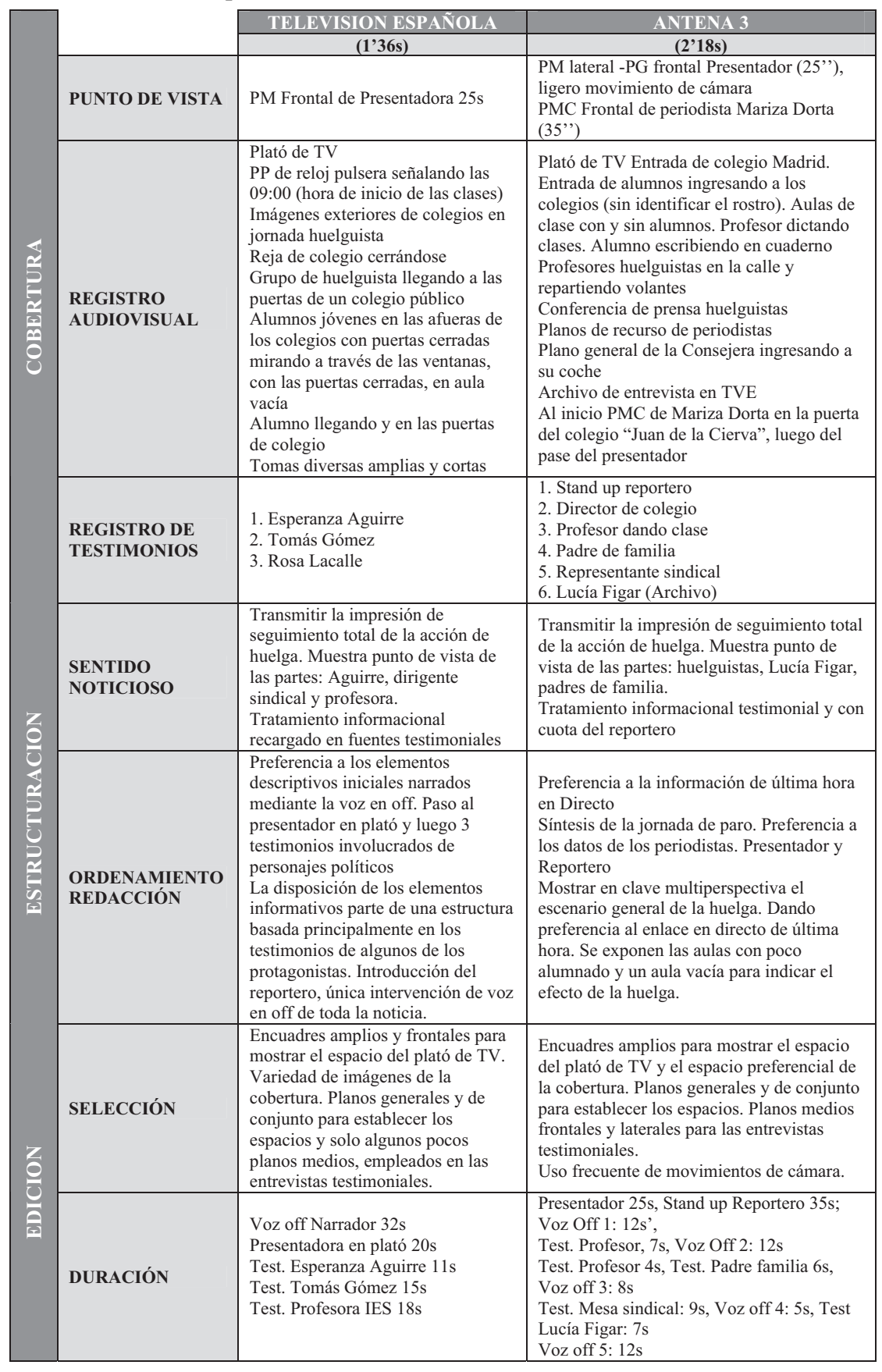




\begin{tabular}{|l|l|l|l|}
\hline $\begin{array}{l}\text { AJUSTE } \\
\text { TEMPORAL } \\
\text { DEFINITIVO }\end{array}$ & $\begin{array}{l}\text { Entrada 32s } \\
\text { Cuerpo 46s } \\
\text { Cierre: } 18 \mathrm{~s}\end{array}$ & $\begin{array}{l}\text { Entrada: 1m/Plató+Stand up } \\
\text { Cuerpo: 66s } \\
\text { Cierre: } 12 \mathrm{~s}\end{array}$ \\
\hline \multirow{2}{*}{ TITULACIÓN } & $\begin{array}{l}\text { Primer día de huelga en los } \\
\text { institutos } \\
\text { Según los sindicatos seguida por el } \\
90 \% \text {. Según la Comunidad de } \\
\text { Madrid por el 43\% } \\
\text { Marta Jaumandreu } \\
\text { Esperanza Aguirre }\end{array}$ & $\begin{array}{l}\text { Sin títulos ni especificación de testigos } \\
\text { salvo en el caso de la mención a las } \\
\text { declaraciones de Lucía Figar }\end{array}$ \\
\hline SONORIZACIÓN & $\begin{array}{l}\text { No hay empleo de sonidos } \\
\text { adicionales al de los testigos y } \\
\text { locutor }\end{array}$ & $\begin{array}{l}\text { Sonido de ambiente de exteriores de } \\
\text { colegios. } \\
\text { Sonido de fondo ambiental leve durante la } \\
\text { emisión del Stand up de la reportera }\end{array}$ \\
\hline
\end{tabular}

El análisis comparativo de ambas noticias muestra diferencias importantes en el tratamiento del contenido, la articulación expresiva del mensaje, así como del sentido que finalmente transmiten ambos discursos. Veamos en qué aspectos puntuales se advierten las diferencias con mayor claridad. Para ello tomamos como referencia de comparación las tres fases del proceso de construcción informativa antes mencionado.

\section{Fase 1: Cobertura}

Punto de vista: La localización predominante de la cámara en ambas notas es frontal a la acción que se representa. En el caso de TVE (Televisión Española), se aprecia únicamente una toma en PMC de la presentadora desde el plató, mientras que Antena 3 (A3) muestra un Plano Medio, de enfoque lateral del presentador y pasa a un Plano General, con ligero movimiento de cámara vertical (hacia arriba), hasta mostrar la imagen de la periodista en el monitor. Seguidamente se produce un fundido encadenado a la imagen de la periodista Mariza Dorta tomada en un Plano Medio Corto, informando en directo desde la fachada de un colegio de la ciudad de Madrid. Este diseño da énfasis a la información de última hora con presencia explícita del periodista «En Directo». Mientras TVE solo incluye a la presentadora desde el propio plató luego de un breve vídeo de entrada donde se resume la jornada huelguista. La secuencia frente a la cámara de A3 tiene una duración de 1 minuto e incluye tanto plató como exteriores, mientras que en TVE la misma descripción se efectúa en solo 20 segundos y únicamente muestra al periodista informando desde el interior de la televisora.

Registro audiovisual: El planteamiento de la captación de imágenes es bastante similar en ambas coberturas. Viene condicionado por las características propias de los espacios relacionados con la información principal. No obstante, pueden observarse algunas diferencias notables. En las dos noticas la composición otorga preferencia a planos amplios con función descriptiva: maestros reunidos dentro y fuera de los centros, grupos de alumnos que entran y salen. En ambos casos se ve expresamente imágenes parciales de alumnos y maestros que se encuentran tras las rejas y el acceso restringido por la huelga. En los interiores se graban las aulas con escaso alumnado e incluso vacías. En la cobertura de TVE encontramos distintas imágenes acompañadas de movimientos de cámara (panorámicas desde planos cortos de las carpetas hasta el atril del profesor o de la entrada de los colegios). Contrariamente las imágenes registradas por A3 suelen ser mayormente planos estáticos, pero con movimiento intenso 
de las personas. Igualmente, el empleo de testimonios de profesores en su propio espacio de trabajo constituye una característica exclusiva de la nota de A3. Solo TVE emplea un video de archivo donde muestra las declaraciones de la consejera en otro espacio de la cadena. No hay evidencia certera que la imagen que utiliza A3 para mostrar a la consejera de educación corresponda a una grabación hecha el mismo día (se le ve aparentemente evasiva). La distancia de la cámara respecto del personaje deja abierta la opción que la imagen sea un material de archivo.

Registro de testimonios: TVE muestra tres declaraciones y las hilvana de forma consecutiva. El orden define la jerarquía respecto de los personajes políticos involucrados en el hecho. Primero muestra a la Presidenta de la Comunidad de Madrid Esperanza Aguirre, luego a Tomás Gómez, Secretario General del PSOE (Madrid) y finalmente a la profesora Rosa Lacalle. La duración total de las declaraciones alcanza los 44s. A3 por el contrario ofrece un enfoque testimonial más amplio y distribuido. Muestra al director de un colegio, a un profesor que decide no hacer huelga, a un representante sindical y finalmente a un padre de familia. Solamente la noticia de A3 posee el stand up de la periodista y se coloca al inicio, inmediatamente después de la presentación del conductor en el plató.

\section{Fase 2: Estructuración}

Sentido noticioso: El diseño de TVE propone un esquema de tratamiento integral sintético de la huelga. Muestra punto de vista de las partes involucradas pero dando una preferencia especial al enfoque político alrededor de la medida de protesta y sus efectos en la acción política de la Comunidad. Muestra a Esperanza Aguirre, un dirigente sindical y solo una profesora; para con ellos intentar dejar establecida una multiperspectiva. A3 desarrolla un modelo estructural con una distribución más amplia de fuentes testimoniales que incluye a profesores no huelguistas y un padre de familia. El valor añadido de la inmediatez se fortalece con la inclusión del stand up de reportero. Ambas noticias desarrollan un modelo informativo dotado de claridad, coherencia informativa, orden lógico de datos y fuentes exhibidas.

Ordenamiento y redacción: En ambos casos se otorga preferencia a los elementos descriptivos iniciales narrados mediante la voz en off, aunque el tiempo de la presencia del reportero sea notoriamente desigual. TVE concentra el peso en los datos testimoniales directos de políticos, intenta equilibrarlo con la voz del periodista en plató (32s) y en la sección final mediante las declaraciones de políticos de la comunidad afectada. Este procedimiento se orienta claramente a complementar la información resumida de la jornada, expuesta en el único vídeo editado. Prevalece el orden y la descripción detallada de los hechos. Mientras TVE esboza un repaso de toda la jornada en pocos segundos mediante imágenes variadas, haciendo énfasis en que los huelguistas han respetado los servicios mínimos e indica en el texto y los títulos los porcentajes de participación de ambos grupos. A3 opta por intervenciones fragmentadas que alternan sucesivamente los textos del reportero con las distintas declaraciones de los testigos desarrollando una narración orientada a describir la evolución de la jornada. Esta última propuesta informativa resulta siendo más dinámica y acorde para mostrar adecuadamente la variedad de fuentes involucradas en el hecho. En el se- 
gundo caso, A3, el texto leído por el periodista menciona directamente al testimonio que viene a continuación. Mediante este recurso el mensaje facilita la concatenación de fuentes y perspectivas suministradas. En todo momento las imágenes mantienen una exacta correspondencia con el sonido, conectando así directamente la corriente audiovisual de la información.

\section{Fase 3: Edición}

Selección: TVE plantea el esquema de montaje recurriendo mayoritariamente un encuadres amplio y frontal para mostrar el espacio del plató de TV. La secuencia visual de montaje comienza con la imagen en primerísimo primer plano de un reloj marcando las 8 de la mañana (hora de ingreso a clases). La toma cambia a una vista general de la reja de entrada de un colegio cerrándose, indicando claramente una situación restrictiva. Seguidamente se muestra una cadena de imágenes principalmente desde los exteriores de un colegio, para mostrar la situación que se experimenta en los alrededores de los centros donde se ha producido la cobertura informativa. Se escogen planos cortos para mostrar a los alumnos llegando a los centros, pequeños grupos en la puerta y del interior. En todas las imágenes próximas se evita intencionalmente mostrar los rostros de los menores, grabándoles de espaldas, a distancia o de costado para evitar que sean identificados. Las secuencias se complementen con objetos como libros, cuadernos o las mochilas de los alumnos. El esquema de A3 es un tanto diferente. La sección en plató es bastante convencional. Se inicia con el plano medio lateral del presentador. A los pocos segundos da paso a una imagen general que deja ver en el fondo el monitor donde ya se encuentra la reportera desde el lugar de la cobertura. En ese momento se produce un breve diálogo para dejar establecido la realización en directo del enlace. Cuando la imagen cambia y muestra solo a la periodista, esta aparece en un plano medio corto delante de la fachada de un colegio. En la sección de del vídeo editado, el esquema recurre preferentemente a planos generales y de conjunto para definir en pantalla los espacios exteriores, mientras que los planos cortos para las entrevistas testimoniales que se presentan en el segundo bloque. No existen encuadres de tamaño intermedio que puedan ser utilizados en ambos espacios. Al parecer ya existe un protocolo de dimensión de las imágenes según las características del lugar de cobertura (interiores, exteriores, con o sin personas). En algunos casos se observan encuadres laterales para aprovechar la perspectiva del interior de las aulas vacías o con escaso alumnado. Los planos medios frontales y laterales se usan en las entrevistas testimoniales y resaltan la figura del personaje hablante. Finalmente, se observa un una elección frecuente de movimientos de cámara que contribuyen a dinamizar el discurso y añadir un toque de variedad a un discurso relativamente previsible.

Duración: TVE los planos, independientemente de su contenido tienen una duración prácticamente métrica que oscila entre 1 y 2 segundos cuando las imágenes van acompañadas de la voz del reportero, que en su única intervención narra un texto de 32s conteniendo imágenes diversas. La estructura por bloques indica los siguientes tiempos: Presentadora en plató 20s. Declaraciones de Esperanza Aguirre 11s. Declaraciones de Tomás Gómez 15s, Declaraciones de Profesora IES 18s. Si bien Aguirre 
va al inicio en la lista de testimonios, se comprueba que las declaraciones del opositor son más extensas en 7 segundos y de la profesora, que se insertan en el final llegan a 18 segundos. En las declaraciones no se añaden ningún tipo de imágenes de apoyo. A3 presenta una estructura un tanto atípica. El tiempo de los periodistas frente a cámara tiene una duración equivalente a 1 minuto. El Presentador desde el plató alcanza los $25 \mathrm{~s}$, mientras que el Stand up del reportero es de $35 \mathrm{~s}$. Las voces en off de la periodista se fragmentan en cuatro intervenciones $1^{\circ}$ de $12 \mathrm{~s}, 2^{\circ}$ de $12 \mathrm{~s}, 3^{\circ} 8 \mathrm{~s}, 4^{\circ}$ de $5 \mathrm{~s}$ y $5^{\circ} 4 \mathrm{~s}$. Los testimonios igualmente se disponen con bastante equilibrio Profesor 1: $7 \mathrm{~s}$, Profesor 2: 4s, Padre familia: 6s, Dirigente sindical: 9s, Lucía Figar: 7s. Se trata de únicamente de frases muy breves y significativas, indicando su posición favorable o en contra de la paralización.

\section{Fase 4: Emisión}

Ajuste temporal definitivo: TVE desarrolla los siguientes bloques: Entrada 32s, Cuerpo 46s, Cierre: 18s. A3 Entrada: Plató+Stand up: 1m, Cuerpo: 1m 06s y Cierre: $12 \mathrm{~s}$

Sonorización: TVE no emplea sonidos adicionales a los testigos y el locutor. Se percibe un ligero sonido de ambiente de exteriores de colegios como fondo. A3 recurre al sonido ambiental leve durante la emisión del Stand up, pero durante las secuencias editadas solo se advierte el sonido de las voces declarantes.

Titulación: TVE Primer día de huelga en los institutos. Según los sindicatos seguida por el 90\%. Según la Comunidad de Madrid por el 43\%. Marta Jaumandreu, Esperanza Aguirre. A3 Sin títulos ni especificación de testigos salvo en el caso de la mención a las declaraciones de Lucía Figar.

\section{Segundo Nivel: Intención informativa}

En este nivel de construcción de sentido informativo el objetivo de ambos mensajes se ciñe principalmente a la transmisión amplia, variada y correcta de la información, con un criterio basado en la actualidad, con el empleo de datos testimoniales de fuentes directamente implicadas. Sin embargo, los procedimientos de organización de los materiales audiovisuales registrados en ambas piezas dejan entrever la presencia de algunos expositivos particulares. La propuesta periodística de TVE plantea un esquema identificable como lineal cronológico, con un desarrollo alternado basado en la pluralidad de perspectivas basado en unas pocas fuentes. La primera sección de la noticia se encauza en mostrar una breve síntesis de la jornada, apelando a un orden estrictamente secuencial: hechos, contextos y escenarios representativos durante el día. En la segunda sección, la periodista desde el plató, revisa los hechos y los complementa recurriendo a información estadística del seguimiento de la huelga. La tercera sección se centra en las declaraciones y expone el balance de la huelga desde tres personajes: Aguirre, Gómez y una profesora. El diseño, en este caso, mantiene la cronología de los hechos, pues las manifestaciones respecto del balance son posteriores 
a la realización de la protesta; así, mediante la alternancia de las afirmaciones la noticia construye un esquema paralelo del suceso. El uso de títulos incorpora información estadística complementaria para explicitar numéricamente el seguimiento de la medida, remarcando a su vez la presencia de los testimonios, orientándolos con el sentido de las imágenes, en tanto que poseen contenidos parecidos. Por su parte, el planteamiento de A3 otorga mayor peso a la información actual y establece la conexión directa para ofrecer al televidente la información de última hora entre los datos de la televisora y el despacho en vivo del periodista de la tarde. El flujo transmite una corriente de información continua y directa desde el propio lugar de los hechos. El tiempo de este segmento es equivalente al cincuenta por ciento del total de la noticia. Luego se difunde el vídeo con el resumen de la jornada. Este segmento se hilvana correlacionalmente con las entradas de ambos periodistas y articula una transición entre el pasado inmediato y el momento actual, que se alterna en tres oportunidades con los elementos testimoniales mencionados previamente. La intención informativa en ambas noticias es narrar el hecho de forma sintética por los periodistas y complementarlo con el referente directo de las fuentes involucradas.

\section{Tercer Nivel: Nivel de la percepción espacio-temporal}

En el tercer de construcción de la noticia podemos distinguir los siguientes aspectos relevantes. La realización de ambos mensajes se adecúa a un esquema perceptivo coherente. Las imágenes siguen un esquema lógico, dotado de continuidad espaciotemporal permanente y muestran en casi todo momento en perspectiva frontal a los personajes encuadrados a una distancia natural de relación interpersonal, equivalente al nivel de importancia que se otorga finalmente en la representación en su conjunto. Cuando esto no es posible por las dificultades de la cobertura, se muestran encuadres laterales, incluso inestables, pero que siempre permiten reconocer completamente al personaje. El diseño de composición visual mediante la cámara sugiere un modo directo y naturalista de reproducción de la escena a través de los recursos de tamaño y ángulo, preferentemente normales y de posición frontal. Los movimientos de acción interna son frecuentes por las características de la noticia, así como los recursos ópticos, pero cuando se emplean son solo para producir perspectiva, una sensación máxima de profundidad de campo en espacios reducidos o para adecuar el rodaje al desenvolvimiento de los actores de la noticia. En estas situaciones los camarógrafos apelan a los movimientos de cámara de corto recorrido y suave desplazamiento, para que no afecten la correcta lectura del texto e incrementar la impresión de movilidad. El esquema de montaje está basado siempre en el raccord y la linealidad de las acciones. El salto temporal es admitido cuando es mínimo, pero en definitiva depende de la lógica y coherencia temática del hecho, que puede admitir algún pequeño desorden en la ocurrencia real y cronológica de los registros, pero al ser desconocidos por el televidente, quedan unificados perfectamente por el sentido mismo del mensaje. Igualmente, se insiste frecuentemente en remarcar la coherencia audiovisual, la imagen expresa un significado igual al canal sonoro, es reiterativo o complementario y transmite siempre un sentido exacto de los hechos. Solo en A3 se registra un adelantamiento intencional del sonido respecto de la imagen -overlapping- (MorALES, 
2010b) y es utilizado para vincular la voz en off del periodista con el testimonio; es decir, partes formantes de un mismo segmento. En TVE la misma información es subrayada con el uso de títulos localizados en la parte inferior izquierda de la pantalla.

\section{Conclusiones}

El seguimiento estricto de las normas y procedimientos de estructuración del discurso escrito y audiovisual son fundamentales para conseguir de la noticia televisiva un mensaje claro, directo y completo, ceñido a la evolución temporal de un hecho concreto y de la presencia de actores vinculados, habitualmente conocidos previamente por las audiencias. Pese a los cambios en los modelos productivos y el desarrollo de herramientas de realización y tratamiento de vídeos, las noticias para televisión, en su base más primitiva, se construyen siguiendo el mismo paradigma de organización interna de la prensa escrita, radiofónica y de las normas clásicas empleadas en la construcción de los productos argumentales. La fórmula ternaria: Presentación-Desarrollo-Conclusión, sigue funcionando plenamente como esquema base de la transmisión ordenada y correcta de la información. Y, en este caso, los recursos propios de la narrativa audiovisual la mejoran, hacen hincapié en los datos e hilvanan armónicamente los contenidos, que por su propia «ocurrencia» en la realidad pueden sucederse en espacios y tiempos diferentes. Así, los procedimientos del montaje ayudan a concatenar secciones cuya procedencia y características pueden contravenir la construcción mental de un esquema perceptivo totalmente lógico, coherente y secuencialmente cronológico, tal y como sucede en la realidad. Por ejemplo, la inserción de títulos suplementarios, imágenes de apoyo de archivo relacionadas, la anticipación de nombres de los testigos por el texto en off, el adelantamiento intencional de la imagen o el sonido o el uso de transiciones visuales, entre otros, pueden ayudar de manera significativa a mejorar la claridad narrativa y añadirle incluso, pinceladas estético expresivas con el fin de imprimirle un sello característico a la noticia, al programa informativo y la cadena por la cual se emite.

Pero sobre la base de los hechos acontecidos se superpone el factor interpretativo, la forma de ver, la forma de contar la noticia y esos factores son los que definen su propia personalidad, marcando unas diferencias cuando la vemos tratada por dos cadenas distintas. La forma de ver, corresponde al punto de vista que asume el periodista y la cámara para construir la escena audiovisual. Es por tanto una variable de composición dimensional, de distancia y tamaño, que depende en definitiva de la localización física del camarógrafo respecto de la situación y/o del punto de vista que desea o pueda proyectar al espectador. Este es un primer nivel. El segundo nivel está formado por la segunda estructuración que se hace a posteriori, al momento de ponderar el material, haciéndolo coincidir con el punto de vista o posicionamiento del medio, destacando unos elementos sobre otros y ordenándolos en una extensión variable de tiempo regulada por la importancia de tiempo que finalmente se decide asignarle. Es a partir del resultado de esa segunda articulación que surgen las diferencias manifiestas entre las dos noticias. El análisis comparativo aplicando el MOCIAE ha sido útil para diferenciar los tratamientos empleados en ambas noticias y para diseccionar cuáles son las decisiones y estrategias llevadas a cabo en cada fase de la producción. También 
para conocer cuál es el sentido que producen en un determinado orden. Por tanto, no se ha pretendido juzgar la orientación ideológica o política que puede subyacer al texto noticioso de las noticias emitidas por Televisión Española o Antena 3, ni el peso de la elección de las fuentes testimoniales. Pero, la medición de su extensión, variedad datos y fuentes representan indicadores objetivos de la importancia y el enfoque que se pretende otorgar a la noticia por el valor individual que adquiere cada parte y el equivalente a la suma total de elementos enunciados.

En el presente artículo se ha intentado articular coherentemente cada una de etapas del proceso de producción de noticias para la televisión, a partir de la explotación de sus distintos recursos y métodos de trabajo, con la intención de optimizar no solo las rutinas que involucran su construcción. Se ha puesto a prueba el modelo aplicándolo al análisis de dos noticias emitidas por cadenas diferentes y ha permitido localizar diferencias significativas en ambos casos. El modelo pretende ser una herramienta a través del cual los profesionales y académicos del periodismo pueden localizar y enmendar las deficiencias ocurridas en las diferentes instancias de la producción y explotarlas comunicativamente en términos audiovisuales para el beneficio de la claridad informativa y la eficacia en el control de la atención, el seguimiento y el posterior recuerdo de los mensajes.

\section{Referencias Bibliográficas}

AMIEL, Vincent (2005): Estética del montaje. Madrid, Abadía

BALÀZS, Béla (1987): El Film: evolución y esencia de un arte nuevo. Barcelona, Gustavo Gili

BANDURA, Albert (1977): "Self-efficacy: Toward a unifying theory of behavioral change" Pychological Review, v.84, p. 191-215.

CASSANY, David. (1987): Descriure escriure: com s'aprèn a escriure. Barcelona, Empúries

CASASÚS, Josep María y NÚÑEZ LADÉVEZE, Luis (1991): Estilo y Géneros Periodísticos, Barcelona, Ariel

CHION, Michael (2001): La Audiovisión: introducción a un análisis conjunto de la imagen y el sonido. Barcelona, Paidós.

CRIGER, Ann, MARION, Just, y NEUMAN, W. Russel (1994): "Interpreting visual versus audio messages in television news". Journal of communication, 44(4), 132149

DEL REY DEL VAL, Pedro. (2002): Montaje: Una profesión de cine. Madrid, Ariel.

D'YDEWALLE, Gery y GERMEYS, Filip (2005): “The psychology of film: perceiving beyond the cut". Psychological Research. Oct 8: 1-9 16215744 (P,S,E,B,D).

FERNÁNDEZ DEL MORAL, Javier (1993): Fundamentos de la Información Periodística Especializada. Madrid, Síntesis 
FIELD; Syd (2001): El Manual del guionista: ejercicios e instrucciones para escribir un buen guión paso a paso, $4^{\mathrm{a}}$ edición. Madrid, Plot.

HUERTAS, Amparo y PERONA, Juan José (1999): Redacción y locución en medios audiovisuales. Barcelona, Bosch

LÁZARO, Fernando (1993): "Prólogo" en Libro de Estilo de ABC. Barcelona, Ariel

LÓPEZ, Ángel (1996): Escritura e Información: La Estructura del Lenguaje Periodístico. Madrid, Cátedra

MARTÍN, Marcel (1999): El Lenguaje del cine. Barcelona, Gedisa

MASCELLI, Josep (1998): Los cinco principios básicos de la cinematografia Manual del montador de cine. Barcelona, Bosch.

MAS, Lluís. (2011): "Modelo superestructural de la noticia en Televisión". Estudios del Mensaje periodístico, vol. 17, núm. 1 (enero-junio). Madrid, Servicio de Publicaciones de la Universidad Complutense, pp. 95-116.

MAY, John. y BARNARD, Philippe. (2003): "Using Film Cutting Techniques in Interface Design". Human-Computer Interaction, vol. 18, Issue 4, February, pages 325- 372

METZ, Christian. (2002): Ensayos sobre la significación en el cine. Barcelona, Paidós

MILLERSON, Gerard. (2001): Realización y producción en televisión. $4^{\circ}$ Edición. Madrid, Instituto Oficial de Radio y Televisión.

MITRY, Jean (2002): Estética y psicología del cine. $5^{\mathrm{a}}$ ed. Barcelona, Siglo XXI

MORALES, Fernando (2000): Teoría y práctica de la edición en video. Lima, Edit. Universidad de San Martín de Porres, Escuela Profesional de Ciencias de la Comunicación

MORALES, Fernando (2010a): "Forma y estructura discursiva de la noticia audiovisual. Una propuesta para su estudio y análisis de sus efectos de sentido". Perspectivas de la Comunicación, vol. 3, nº 1, pp. 7-19. Temuco, Chile, Universidad de La Frontera.

MORALES, Fernando (2010b): Diseño de un modelo para el estudio del impacto perceptivo del overlapping o encabalgamiento audiovisual. Tesis doctoral, Universidad Autónoma de Barcelona

REISZ, Karel \& MILLAR, Gavin (2003): Técnica del montaje cinematográfico. Madrid, Plot.

RODERO, Emma (2003): Locución radiofónica. Madrid, Instituto Oficial de Radio y Televisión

SADOSKY, Mark. y Paivio, Andreu (2001): Imagery and text. A dual coding Theory of reading and writing. Mahwah, $\mathrm{Nj}$ : Lawrence Erlbaum Associates. 
SÁNCHEZ, Rafael (2003): Montaje cinematográfico: arte de movimiento. Buenos Aires, La Crujía.

SMITH, Tim (2005): "Editing Time: an empirical investigation of time perception across match action cuts". Paper presented to the Society for Cinema and Media Studies. London, UK

TABOADA, Maite y MANN, William (2005): "Rhetorical Structure Theory: looking back and moving ahead". Discourse Studies, v. 8, n. 3, p. 423-459

VAN DIJK, Teun A. (1990): La noticia como discurso: comprensión, estructura y producción de la información. Barcelona, Paidós

WESTLEY, B. H., \& MACLEAN, M.S. Jr. (1957): “A conceptual model for communications research". Journalism Quarterly, 34(31-38)

WURTZEL, Alan (1983): Television production. New York, McGraw-Hill. 